\title{
Penile strangulation: An unusual sexual practice that often presents an urological emergency
}

\author{
Lucio Dell'Atti \\ Department of Urology, Arcispedale "S. Anna", Ferrara, Italy
}

\begin{abstract}
Summary Placement of constricting devices around the penis for autoerotic purposes or increasing of sexual performance represents a well-known challenge for urologists. Penile incarceration is a urologic emergency with potentially severe clinical consequences. In many cases a rapid intervention and a sudden removal of the foreign body it is enough so that patients need no further intervention. We report three different cases of strangulating objects (metallic ring, metal bearing and plumbing pipe) presented at our emergency department and three different methods of devices extraction practiced. Remove these devices can be challenging and often requires resourcefulness and multidisciplinary approach.
\end{abstract}

KeY WORDS: Penile strangulation; Ring; Penis; Ischemia.

Submitted 11 November 2013; Accepted 31 December 2013

\section{Case Report}

The frequency of self-injuries on penis is currently increasing in certain cultures. The aim of their use may be to enhance the sexual performance, to prolong the erection, to achieve erotic or auto-erotic effects or simply sexual curiosity $(1,2)$. Penile incarceration is a rare but serious problem, which can easily lead to strangulation and infarction. Therefore it is a urological emergency that needs a quick treatment in order to prevent long-tail claims. Failure in removing those devices can lead to significant ischemia and loss of tissue (3). The treatment of penile strangulation is decompression of the constricted penis to facilitate free blood flow and micturition (4).

We report three cases of penile strangulation that have been presented at our attention.

Case report and Figures are posted in Suppementary materials on www.aiua.it

\section{Discussion}

There are sporadic reports of penile strangulation in the medical literature (5).

This condition is not common, but it is certainly a urological emergency as prompt removal of the constricting object and the decompression of the penis are required to prevent long-term complications (6). Strangulation may occur when various items, made of metal or non-metal material, are pulled over the penis. Non-metallic objects can cause much more serious injuries, but they are more easily removed than metal objects. The reason for the higher level of damage in case of non-metallic objects is that they are more elastic and can therefore exert a greater pressure on the penis (2). Among the objects pulled onto the penis there are: metal rings, wedding rings, iron sleeves, nuts, pipes, bearings, bicycle parts, all kinds of bottles, tools and rubber bands. Objects pulled onto or wound round the penis can cause mechanical damage. Clamping of the penis causes venous stasis or blockage. As result of venous stasis, the penis lymph vessels and arteries may be blocked, with consequence of ischaemia or infarction (5). After several hours, necrosis and gangrene may develop. In some case, such as ours, not only the penis, but also the scrotum is ligated. The most important task is to remove the foreign body, which can involve serious technical difficulties in the case of metal devices. An equipment with various tools is essential for a successful removal of different forms of strangulating object. This is followed by conservative or surgical treatment of the damaged tissue of penis. In these cases a psychological or psycho-sexual evaluation of the patients seems to be suitable, but unfortunately our patients refused any further assessment.

\section{REFERENCES}

1. Osman M, al Kadi H, al Hafi R. Gangrene of the penis due to strangulation by a metallic ring. Scand J Urol Nephrol. 1996; 30:77-78.

2. Perabo FG, Steiner G, Albers P, Muller SC. Treatment of penile strangulation caused by costricting devices. Urology. 2002; 59:137.

3. Ivanovski $O$, Stankov $O$, Kuzmanoski M, et al. Penile strangulation: two case reports and review of the literature. J Sex Med. 2007; 4:17751780.

4. Pannek J, Martin W. Penile entrapment in a plastic bottle. J Urol. 2003; $170: 2385$

5. Noh J, Kang TW, Heo T, et al. Penile strangulation treated with the modified sting method. Urology. 2004; 64:591.

6. Kimber RM, Mellon JK. The role of special cutting equipment and corporeal aspiration in the treatment of penile incarceration with a barbell retaining collar. J Urol. 2004; 172:975.

\section{Correspondence}

Lucio Dell'Atti, MD, PhD (Corresponding Author) dellatti@hotmail.com

Department of Urology, Arcispedale "S. Anna",

Via A. Moro 8 - 44124 Cona, Ferrara, Italy 